\title{
Randomized trial of hematocrit $25 \%$ versus $35 \%$ during hypothermic cardiopulmonary bypass in infant heart surgery
}

Jane W. Newburger, MD, MPH, ${ }^{\text {a,h }}$ Richard A. Jonas, MD, ${ }^{\text {, g, }, *}$ Janet Soul, MD, ${ }^{c, j}$ Barry D. Kussman, MBBCh, d,i David C. Bellinger, PhD, MSc, ${ }^{c, j}$ Peter C. Laussen, MD, ${ }^{a, i}$ Richard Robertson, MD, ${ }^{e, k}$ John E. Mayer Jr, MD, ${ }^{b, g}$

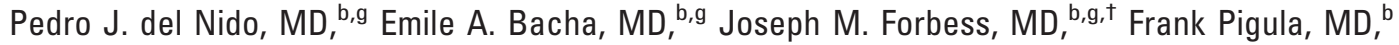

Stephen J. Roth, MD, MPH, ${ }^{a}$ Karen J. Visconti, PhD, ${ }^{b}$ Adre J. du Plessis, MBChB, MPH, ${ }^{c, j}$ David M. Farrell, MA, CCP, Ellen McGrath, RN, ${ }^{a}$ Leonard A. Rappaport, MD, ${ }^{\mathrm{f} h \mathrm{~h}}$ and David Wypij, $\mathrm{PhD}^{\mathrm{a}, \mathrm{h}, \mathrm{l}}$

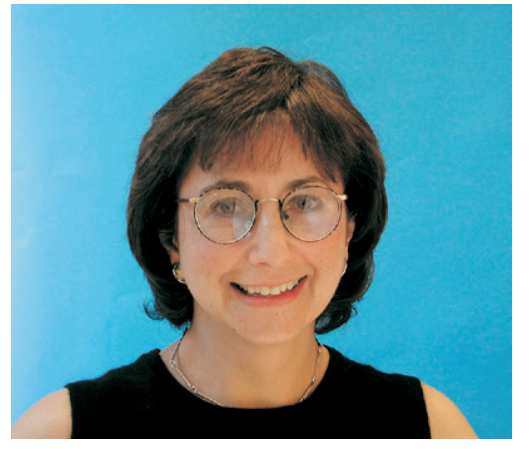

Dr Newburger

See related articles on pages 240 and 355 .

Supplemental material is available online.
Objectives: We previously reported that postoperative hemodynamics and developmental outcomes were better among infants randomized to a higher hematocrit value during hypothermic cardiopulmonary bypass. However, worse outcomes were concentrated in patients with hematocrit values of $20 \%$ or below, and the benefits of hematocrit values higher than $25 \%$ were uncertain.

Methods: We compared perioperative hemodynamics and, at 1 year, developmental outcome and brain magnetic resonance imaging in a single-center, randomized trial of hemodilution to a hematocrit value of $25 \%$ versus $35 \%$ during hypothermic radiopulmonary bypass for reparative heart surgery in infants undergoing 2-ventricle repairs without aortic arch obstruction.

Results: Among 124 subjects, 56 were assigned to the lower-hematocrit strategy (24.8\% $\pm 3.1 \%$, mean $\pm \mathrm{SD}$ ) and 68 to the higher-hematocrit strategy $(32.6 \% \pm 3.5 \%)$. Infants randomized to the $25 \%$ strategy, compared with the $35 \%$ strategy, had a more positive intraoperative fluid balance $(P=.007)$ and lower regional cerebral oxygen saturation at 10 minutes after cooling $(P=.04)$ and onset of low flow $(P=.03)$. Infants with dextro-transposition of the great arteries in the $25 \%$ group had significantly longer hospital stay. Other postoperative outcomes, blood product usage, and adverse events were similar in the treatment groups. At age 1 year $(n=106)$, the treatment groups had similar scores on the Psychomotor and Mental Development Indexes of the Bayley Scales; both groups scored significantly worse than population norms.

Conclusions: Hemodilution to hematocrit levels of 35\% compared with those of $25 \%$ had no major benefits or risks overall among infants undergoing 2-ventricle repair. Developmental outcomes at age 1 year in both randomized groups were below those in the normative population.

\footnotetext{
From the Departments of Cardiology, ${ }^{\mathrm{a}}$ Cardiovascular Surgery, ${ }^{\mathrm{b}}$ Neurology, ${ }^{\mathrm{c}}$ Anesthesiology, ${ }^{\mathrm{d}}$ Radiology, ${ }^{\mathrm{e}}$ and Pediatrics, ${ }^{\mathrm{f}}$ at Children's Hospital Boston; the Departments of Surgery, ${ }^{\mathrm{g}}$ Pediatrics, ${ }^{\mathrm{h}}$ Anesthesia, ${ }^{\mathrm{i}}$ Neurology, ${ }^{\mathrm{j}}$ and Radiology ${ }^{\mathrm{k}}$ at Harvard Medical School; and the Department of Biostatistics, ${ }^{1}$ Harvard School of Public Health, Boston, Mass.

Registered with clinicaltrials.gov (\#) NCT00006183

Supported by grants HL 063411 and RR 02172 from the National Institutes of Health and by the Farb Family Fund.

Received for publication Oct 11, 2006; revisions received Jan 9, 2007; accepted for publication Jan 29, 2007.

Address for reprints: Jane W. Newburger, MD, MPH, Department of Cardiology, Children's Hospital Boston, 300 Longwood Ave, Boston, MA 02115 (E-mail: jane.newburger@cardio.chboston.org).

*Dr Jonas is currently Chief of Cardiovascular Surgery and Co-director of the Children's National Heart Institute, Washington, DC.

$\dagger$ Dr Forbess is currently at Children's Medical Center Dallas.

J Thorac Cardiovasc Surg 2008;135:347-54

$0022-5223 / \$ 34.00$

Copyright @ 2008 by The American Association for Thoracic Surgery

doi:10.1016/j.jtcvs.2007.01.051
} 


\author{
Abbreviations and Acronyms \\ $\mathrm{CPB}=$ cardiopulmonary bypass \\ D-TGA $=$ dextro-transposition of the great arteries \\ DTI = diffusion tensor imaging \\ MDI = Mental Development Index \\ MRI = magnetic resonance imaging \\ MRS = magnetic resonance spectroscopy \\ PDI = Psychomotor Development Index \\ PRISM $=$ Pediatric Risk of Mortality \\ TOF $=$ tetralogy of Fallot \\ VSD $=$ ventricular septal defect
}

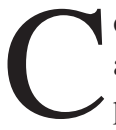

ognitive impairment and hemodynamic instability after infant heart surgery with cardiopulmonary bypass (CPB) have been associated with hemodilution to very low hematocrit values during hypothermic $\mathrm{CPB}$ in reparative infant heart surgery. ${ }^{1}$ However, the optimal hematocrit for use during hypothermic CPB is unknown. To explore the influence of hemodilution during hypothermic CPB on cognitive outcomes, $\mathrm{we}^{1}$ previously conducted a randomized trial of hemodilution to a hematocrit value of approximately $20 \%$ versus $30 \%$ in infants less than 9 months of age undergoing reparative cardiac operations. Hemodilution to $20 \%$ produced outcomes inferior to those at $25 \%$ or greater, but we could not determine a specific target hematocrit level greater than 25\% that was optimal. On the basis of these findings, the Data and Safety Monitoring Board, appointed by the National Institutes of Health, stopped our trial of $20 \%$ versus $30 \%$ hematocrit values and advised us to perform a randomized comparison of $25 \%$ versus $35 \%$ hematocrit values. In the current prospective, randomized, single-center trial, we compared early postoperative course and neurodevelopmental outcome at age 1 year after hemodilution to a hematocrit level of approximately $25 \%$ versus $35 \%$ during hypothermic CPB in infants undergoing reparative cardiac operations.

\section{Materials and Methods \\ Enrollment of Patients}

We enrolled patients between April 2001 and July 2004 at Children's Hospital Boston. Eligibility criteria included reparative heart surgery at less than 9 months of age in three diagnostic groups: (1) dextrotransposition of the great arteries (D-TGA), (2) tetralogy of Fallot with or without pulmonary atresia or truncus arteriosus, and (3) ventricular septal defect (VSD) or complete common atrioventricular canal defect. Exclusion criteria included birth weight less than $2.3 \mathrm{~kg}$, recognizable phenotypic syndrome of congenital anomalies, extracardiac anomalies of greater than minor severity, previous cardiac surgery, or associated cardiovascular anomalies necessitating aortic arch reconstruction or additional open surgical procedures before the planned developmental follow-up. Fluorescent in situ hybridization studies were not performed on all enrolled infants. Parental informed consent was obtained according to the guidelines of our institutional review board.

\section{Study Design}

Participating infants were randomly assigned to undergo hemodilution to a hematocrit level of approximately $25 \%$ versus $35 \%$, with stratification according to surgeon and diagnostic group. Randomization schemes were developed with a permuted blocks design. The surgeons, anesthesiologists, cardiac intensivists, neurologists, and developmental psychologists were blinded to patient treatment assignment.

\section{Anesthesia and Perfusion Methods}

Anesthetic management and other aspects of perfusion on CPB were identical for both treatment groups. The $\mathrm{pH}$-stat strategy was used during core cooling, low-flow hypothermic perfusion, and rewarming up to $30^{\circ} \mathrm{C}$. $^{2}$ We used conventional ultrafiltration during CPB, but not modified ultrafiltration after CPB. Details of anesthesia and perfusion methods are provided in Appendix E1.

\section{Study Outcomes}

Appendix E1 contains detailed methods regarding measurement of study outcomes. In the perioperative period, these included regional cerebral oximetry; transcranial Doppler; serum lactate levels; cardiac output by thermodilution technique ${ }^{3}$; daily collection of data including events, medications, respiratory status, laboratory studies, fluid inputs and outputs, and blood product requirements; bioelectric impedance ${ }^{4}$; inotrope score $^{3}$; and Modified Pediatric Risk of Mortality-III (PRISM III) scores. ${ }^{5}$ At 1 year of follow-up, outcomes include neurologic examination (also performed preoperatively); brain magnetic resonance imaging (MRI), including qualitative evaluation, and volumetric, ${ }^{6-8}$ diffusion tensor imaging (DTI) ${ }^{9}$ and spectroscopy data ${ }^{10,11}$; and developmental evaluation including the Bayley Scales of Infant Development, ${ }^{12}$ which yields scores on two indexes: the Psychomotor Development Index (PDI) and the Mental Development Index (MDI).

\section{Statistical Analyses}

The treatment groups were compared in intention-to-treat analyses. Secondary analyses examined the effect of hematocrit level at the onset of low-flow CPB as a continuous variable. All analyses were adjusted for diagnostic group. Primary outcome variables were serum lactate levels measured 60 minutes after $\mathrm{CPB}$ in the perioperative period and PDI scores at age 1 year. (See online Appendix for full details.)

\section{Results}

Of 270 infants who met eligibility criteria, 126 (47\%) were enrolled in the study. Among the 144 remaining eligible patients, 88 families declined study participation, 55 underwent surgery before informed consent could be obtained, and 1 was enrolled in a competing study. Two subjects were excluded post hoc; 1 subject with D-TGA/VSD had a Rastelli procedure performed rather than an arterial switch operation, and another with D-TGA/VSD was determined intraoperatively to have a coarctation that required repair. Among the remaining 124 study subjects, 56 were assigned 
TABLE 1. Perioperative and operative characteristics according to treatment group

\begin{tabular}{|c|c|c|}
\hline Variable & $25 \%$ Hematocrit $(n=56)$ & $35 \%$ Hematocrit $(n=68)$ \\
\hline & \multicolumn{2}{|c|}{$M e a n \pm S D$} \\
\hline \multicolumn{3}{|l|}{ Preoperative characteristics } \\
\hline Birth weight (kg) & $3.5 \pm 0.6$ & $3.4 \pm 0.5$ \\
\hline Gestational age (wk) & $39.2 \pm 1.3$ & $39.2 \pm 1.2$ \\
\hline Apgar score at $5 \mathrm{~min}$ & $8.5 \pm 1.1$ & $8.7 \pm 0.7$ \\
\hline Age at operation (d), median (range) & $32(2-239)$ & $41(2-264)$ \\
\hline Sex $(\%$ male $)$ & 61 & 65 \\
\hline Race (\% nonwhite) & 25 & 16 \\
\hline \multicolumn{3}{|l|}{ Diagnosis, $\mathrm{n}(\%)$} \\
\hline D-TGA, IVS & $15(27)$ & $11(16)$ \\
\hline D-TGA, VSD & $10(18)$ & $14(21)$ \\
\hline TOF & $15(27)$ & $21(31)$ \\
\hline TOF, PA & $1(2)$ & $2(3)$ \\
\hline Truncus arteriosus & $2(4)$ & $3(4)$ \\
\hline VSD & $12(21)$ & $16(24)$ \\
\hline Complete common AV canal & $1(2)$ & $1(1)$ \\
\hline Ever intubated $(\%)$ & 34 & 37 \\
\hline Intubated at surgery (\%) & 11 & 12 \\
\hline Overall neurologic exam evaluation (\% abnormal) & 66 & 50 \\
\hline \multicolumn{3}{|l|}{ Operative characteristics } \\
\hline Hematocrit level at induction $(\%)$ & $35.0 \pm 6.8$ & $35.5 \pm 6.4$ \\
\hline Hematocrit level at onset of low-flow bypass (\%) & $24.8 \pm 3.1$ & $32.6 \pm 3.5^{*}$ \\
\hline Crossclamp time (min) & $69 \pm 28$ & $65 \pm 29$ \\
\hline Total support time (min) & $110 \pm 38$ & $105 \pm 42$ \\
\hline Total bypass time (min) & $100 \pm 33$ & $95 \pm 33$ \\
\hline Low-flow bypass time (min) & $50 \pm 29$ & $46 \pm 25$ \\
\hline Duration of circulatory arrest (min), median (range) & $1(0-44)$ & $0(0-59)$ \\
\hline None, n (\%) & $28(50)$ & $40(59)$ \\
\hline $1-10$ & $9(16)$ & $6(9)$ \\
\hline $11-30$ & $15(27)$ & $15(22)$ \\
\hline $31-44$ & $4(7)$ & $6(9)$ \\
\hline$\geq 45$ & 0 & $1(1)$ \\
\hline Fluid balance (in minus out) (mL) & $535 \pm 220$ & $403 \pm 265 \dagger$ \\
\hline Intraoperative blood products $(\mathrm{mL})$, median (range) & $246(55-650)$ & $239(50-866)$ \\
\hline
\end{tabular}

$D$-TGA, Dextro-transposition of the great arteries; IVS, intact ventricular septum; VSD, ventricular septal defect; TOF, tetralogy of Fallot; $P A$, pulmonary atresia; $A V$, atrioventricular; $S D$, standard deviation. ${ }^{*} P<.001$ for difference between treatment groups, determined by means of linear regression with adjustment for diagnosis group. $\dagger P=.007$ for difference between treatment groups, determined by means of linear regression with adjustment for diagnosis group.

to the $25 \%$ hematocrit group and 68 to the $35 \%$ hematocrit group. The slight imbalance in randomized assignments resulted from the use of the permuted blocks design with stratification by surgeon and diagnostic group. Demographic characteristics and preoperative history were similar in the treatment groups (Table 1).

\section{Intraoperative Data}

Although the treatment groups differed significantly with regard to the mean hematocrit value at the onset of low-flow CPB $(P<.001$; Table 1), hematocrit levels were similar by 60 minutes after cessation of CPB (Figure E1). The treatment groups were also similar in durations of crossclamp- ing, total support, total bypass, low-flow bypass, and circulatory arrest; in the rates of cooling and rewarming; and in $\mathrm{pH}$ and carbon dioxide levels and tympanic temperatures before and during CPB.

Infants randomized to the $25 \%$ strategy, compared with the $35 \%$ strategy, had a more positive intraoperative fluid balance $(P=.007$; Table 1$)$. They also had lower mean blood pressure at induction $(58 \pm 25$ vs $66 \pm 19 \mathrm{~mm} \mathrm{Hg}$; $P=.05$ ), at onset of bypass ( $40 \pm 12$ vs $46 \pm 15 \mathrm{~mm} \mathrm{Hg}$; $P=.02)$, and at onset of low-flow bypass (28 \pm 10 vs 32 $\pm 11 \mathrm{~mm} \mathrm{Hg} ; P=.07)$. However, the differences in mean blood pressure from the time of induction to these time points were similar in the treatment groups. 
TABLE 2. Postoperative course according to treatment group

\begin{tabular}{|c|c|c|c|}
\hline Variable & $25 \%$ Hematocrit $(n=56)$ & $35 \%$ Hematocrit $(n=68)$ & $P$ value* \\
\hline \multicolumn{4}{|c|}{$M e a n \pm S D$} \\
\hline Lactate 60 min after bypass & $2.9 \pm 1.7$ & $2.8 \pm 1.4$ & .84 \\
\hline $\begin{array}{l}\text { Impedance } \% \text { change from preoperative } \\
\text { to postoperative day } 1\end{array}$ & $-35 \pm 25$ & $-30 \pm 30$ & .23 \\
\hline Average inotrope score over first 24 hours & $10.8 \pm 5.8$ & $12.6 \pm 5.0$ & .05 \\
\hline \multicolumn{4}{|c|}{ Median (interquartile range) } \\
\hline Postoperative blood products (total) (mL) & $96(65,168)$ & $105(45,180)$ & $.38 \dagger$ \\
\hline Days intubated & $1.5(1.1,3.2)$ & $1.7(1.1,2.7)$ & $.90 \dagger$ \\
\hline Days in intensive care unit & $3(2-5)$ & $3(2-4)$ & $.87 \dagger$ \\
\hline Days in hospital & $7(6-9)$ & $6(5-8)$ & $.14 \dagger$ \\
\hline
\end{tabular}

* $P$ values determined by means of linear regression are for differences between treatment groups with adjustment for diagnosis group. $† P$ values determined by means of Wilcoxon rank sum tests are for differences between treatment groups with adjustment for diagnosis group.

Ten minutes after the onset of cooling, serum osmolality in the $25 \%$ hematocrit group tended to be lower than in the $35 \%$ hematocrit group ( $297 \pm 4$ vs $298 \pm 6 \mathrm{mOsm} / \mathrm{L} ; P=.06)$, but this difference may not be clinically important. Osmolalities were similar at the other two points measured (ie, after induction and on reaching $35^{\circ} \mathrm{C}$ tympanic). Intraoperative ionized calcium was significantly lower in the $25 \%$ hematocrit group 10 minutes after the start of rewarming $(0.92 \pm 0.50$ vs $1.24 \pm$ $0.55 \mathrm{mmol} / \mathrm{L} ; P=.001)$ and during warm flow, when reaching $35^{\circ} \mathrm{C}$ tympanic $(1.40 \pm 0.26$ vs $1.55 \pm 0.31 \mathrm{mmol} / \mathrm{L} ; P=$ .008 ). Ionized calcium was similar in the two groups by 60 minutes after cessation of bypass, however.

Intraoperative total blood product use was similar between treatment groups.

Infants in the $25 \%$ hematocrit group, compared with those in the $35 \%$ hematocrit group, had lower regional oxygen saturation at 10 minutes after cooling $(84 \% \pm 9 \%$ vs $88 \% \pm 9 \% ; P=.04)$ and onset of low flow $(84 \% \pm 9 \%$ vs $88 \% \pm 9 \% ; P=.03$ ), as well as a tendency to be lower at the start of rewarming $(82 \% \pm 12 \%$ vs $86 \% \pm 12 \% ; P=$ $.08), 10$ minutes after start of rewarming $(79 \% \pm 17 \%$ vs $82 \% \pm 13 \% ; P=.06$ ), and at resumption of $\mathrm{CPB}$ at full flow $(81 \% \pm 14 \%$ vs $85 \% \pm 11 \% ; P=.07)$; regional oxygen saturation was similar at cessation of bypass, as well as at 60 minutes, 6 hours, and 18 hours later. There were no significant differences in systolic, diastolic, or mean cerebral blood flow velocity by transcutaneous cerebral Doppler at any time intraoperatively or up to 18 hours postoperatively (data not shown).

\section{Postoperative Course}

Serum lactate values 60 minutes after cessation of bypass were not associated with treatment assignment $(P=.84$; Table 2, Figure E2) or with continuous hematocrit level at the onset of low-flow bypass. After stepwise linear regression modeling, higher serum lactate levels were related to longer duration of circulatory arrest $(P<.001)$, age at surgery less than 15 days $(P=.002)$, preoperative intuba- tion $(P=.002)$, and later calendar date of operation $(P=$ $.04)$, but not with treatment randomization $(P=.45)$. The hematocrit groups also had similar mean lactate levels at 3, $9,12,18$, and 24 hours postoperatively (data not shown).

The average hourly inotrope score over the first 24 hours postoperatively was lower among patients in the $25 \%$ hematocrit group than the score among those in the $35 \%$ group $(P=.05$; Table 2$)$. There were no significant differences between treatment groups in modified PRISM III score at 12 and 24 hours or in percent increase in total body water, measured by percent fall in bioelectric impedance from the preoperative period to the first postoperative day. Cardiac outputs were measured by thermodilution every 3 hours postoperatively in a small subgroup of patients $(n=38)$, but there were no significant differences or suggestive trends between the treatment groups at any point or in their nadir. Similarly, the uses of blood and blood products were similar in the treatment groups. Differences between the treatment groups in durations of tracheal intubation or time until discharge from the intensive care unit or hospital did not reach statistical significance (Table 2).

No infants died or had clinical seizures, and the hematocrit groups were similar with respect to other serious adverse events (Table 3 ). There were no adverse events that were possibly or definitely related to treatment assignment or to the study protocol.

\section{Testing at 1 Year}

Of 124 study children, 2 lived outside the country and were not invited for 1-year follow-up. Of the remaining 122 families, 15 refused to participate, 1 completed questionnaires only, and 106 underwent in-person evaluation. Those who were evaluated, compared with those who declined, had parents with significantly higher education $(P=.04)$ and longer hospital stays $(P=.04)$, but were otherwise similar in perioperative characteristics. Subjects randomized to the $25 \%$ hematocrit group, compared with the $35 \%$ hematocrit group, had similar age- and sex-adjusted height 
TABLE 3. Adverse events according to treatment group*

\begin{tabular}{|c|c|c|c|}
\hline Variable & $\begin{array}{l}25 \% \text { Hematocrit } \\
\quad(n=56)\end{array}$ & $\begin{array}{l}35 \% \text { Hematocrit } \\
\quad(n=68)\end{array}$ & $\begin{array}{c}P \\
\text { valuet }\end{array}$ \\
\hline & \multicolumn{2}{|c|}{ No. with adverse event $(\%)$} & \\
\hline Death & 0 & 0 & \\
\hline Cardiac arrest & 0 & 0 & \\
\hline $\begin{array}{l}\text { Chest opened in cardiac } \\
\text { intensive care unit }\end{array}$ & $3(5)$ & 0 & .10 \\
\hline Choreoathetosis & 0 & 0 & \\
\hline Complete heart block & 0 & $1(1)$ & .40 \\
\hline $\begin{array}{l}\text { Extracorporeal membrane } \\
\text { oxygenation }\end{array}$ & 0 & 0 & \\
\hline Reoperation & $1(2)$ & 0 & 1.0 \\
\hline $\begin{array}{l}\text { Hepatic dysfunction (AST } \\
\text { or ALT > } 400 \text { IU) }\end{array}$ & 0 & $1(1)$ & .40 \\
\hline Mediastinitis & 0 & 0 & \\
\hline Necrotizing enterocolitis & 0 & $1(1)$ & .40 \\
\hline $\begin{array}{l}\text { Renal failure (creatinine } \\
\quad>1.5 \text { ) }\end{array}$ & 0 & 0 & \\
\hline Respiratory arrest & 0 & 0 & \\
\hline Clinical seizures & 0 & 0 & \\
\hline Stroke & 0 & 0 & \\
\hline Tamponade & $1(2)$ & 0 & 1.0 \\
\hline Ventricular fibrillation & $1(2)$ & 0 & .41 \\
\hline
\end{tabular}

$A S T$, Aspartate aminotransferase; $A L T$, alanine aminotransferase. *All adverse events occurred in patients with dextro-transposition of the great arteries, except for ventricular fibrillation, which occurred in an infant with truncus arteriosus. $† P$ values, determined by means of stratified exact tests, are for differences between treatment groups with adjustment for diagnostic group.

percentiles $(34 \% \pm 31 \%$ vs $39 \% \pm 28 \% ; P=0.39)$ and weight percentiles $(36 \% \pm 31 \%$ vs $43 \% \pm 32 \% ; P=.15)$.

PDI scores were similar in the treatment groups (Table 4, Figure E3); scores in both groups were much lower than the population norms $(P<.001)$. In models examining the effect of hematocrit level as a continuous variable, no statistically significant associations were found (Figure E4). After stepwise linear regression modeling, higher PDI scores were related to higher birth weight $(P=.005)$ but not to treatment assignment $(P=.85)$ or diagnostic group.

MDI scores also did not differ significantly among the treatment groups (Table 4, Figure E3) and were significantly lower than population means $(P<.001)$. In models examining the effect of hematocrit level as a continuous variable, no statistically significant associations were found. After stepwise linear regression modeling, higher MDI scores were related to higher birth weight $(P<.001)$ and higher family social class $(P=.01)$, but not to treatment assignment $(P=.19)$ or diagnostic group.

Abnormal results of neurologic examinations were common but did not differ in frequency between the treatment groups (57\% in each group, Table 5). The most common reason that the examination was classified as showing ab-
TABLE 4. Scores on developmental tests according to treatment group

\begin{tabular}{|c|c|c|c|}
\hline Test & $\begin{array}{c}25 \% \text { Hematocrit } \\
(n=48)\end{array}$ & $\begin{array}{c}35 \% \text { Hematocrit } \\
(n=58)\end{array}$ & $\begin{array}{c}P \\
\text { value }^{*}\end{array}$ \\
\hline & \multicolumn{2}{|c|}{ Mean $\pm S D$} & \\
\hline $\begin{array}{l}\text { Psychomotor Development } \\
\text { Index }\end{array}$ & $87.0 \pm 15.4$ & $86.6 \pm 16.3$ & .99 \\
\hline Mental Development Index & $\begin{array}{l}93.7 \pm 11.5 \\
\text { No. with low }\end{array}$ & $\begin{array}{l}95.6 \pm 12.0 \\
\text { ore/total no. }\end{array}$ & .38 \\
\hline
\end{tabular}

(\%)

Psychomotor Development Index

$\leq 85$

$\leq 70$

Mental Development Index

$\leq 85$

$\leq 70$

$\begin{array}{ccc}21 / 48(44) & 25 / 58(43) & .85 \\ 9 / 48(19) & 10 / 58(17) & .79 \\ & & \\ 9 / 47(19) & 12 / 57(21) & 1.0 \\ 1 / 47(2) & 1 / 57(2) & 1.0\end{array}$

* $P$ values are for differences between treatment groups, with adjustment for diagnosis group; $P$ values were determined by means of linear regression for continuous outcome variables and stratified exact tests for dichotomous outcome variables.

normal results was because of abnormalities in motor function.

Of the 106 who underwent 1-year evaluation, 48 (45\%) had a brain MRI. Missing MRI scans were due to parental refusal usually related to the need for general anesthesia (55 children, 52\%), cancellations by the anesthesiologist resulting from medical concerns $(2,2 \%)$, and unavailability of an MRI $(1,1 \%)$. Subjects who had an MRI scan were similar, in terms of PDI and MDI scores, as well as head circumference, to those subjects whose parents declined the MRI scan. Results were classified with respect to both anatomic abnormalities and volumetric and DTI analyses (Table 6). Focal or multifocal abnormalities, typically minor findings such as tiny foci suggestive of small amounts of hemosiderin, were detected in 19 (40\%) children in the combined treatment groups. Diffuse abnormalities were less common, and periventricular leukoencephalopathy was found only in 1 child in each treatment group. Minor developmental abnormalities were detected in 4 children.

For the quantitative MRI analysis (Table 6), we adjusted for both diagnosis group and age at the time of MRI scan, because MRI measures change with age owing to normal brain maturation. For the volumetric analysis, the treatment groups did not differ significantly in their overall volume of gray or white matter, cerebrospinal fluid, or the total volume of the brain, cerebrum, or cerebellum. Regional analysis of brain volumes showed that the $25 \%$ hematocrit group, compared with the $35 \%$ hematocrit group, had significantly smaller gray matter volumes in the left and right premotor $(P=.02$ and $P=.05$, respectively) and left and right subgenual regions $(P=.02$ and $P=.003$, respectively). There were no differences in white 
TABLE 5. Neurologic abnormalities according to treatment group

\begin{tabular}{|c|c|c|c|}
\hline Variable & $25 \%$ Hematocrit $(n=47)$ & $35 \%$ Hematocrit $(n=53)$ & $P$ value* \\
\hline & \multicolumn{2}{|c|}{ No. with abnormality/total no. (\%) } & \\
\hline Overall abnormal examination result & $27 / 47(57)$ & $30 / 53(57)$ & .84 \\
\hline Head circumference & & & .42 \\
\hline Microcephaly & $0 / 47$ & $2 / 53(4)$ & \\
\hline Macrocephaly & $2 / 47(4)$ & $2 / 53(4)$ & \\
\hline Special senses (visual or auditory) & $0 / 47$ & $1 / 53(2)$ & .44 \\
\hline Cranial nerves (oculomotor or facial oromotor function) & $3 / 46(7)$ & $5 / 53(9)$ & .72 \\
\hline Motor function (strength, tone, reflexes) & $25 / 46(54)$ & $25 / 53(47)$ & .42 \\
\hline
\end{tabular}

*P values, determined by means of stratified exact tests, are for differences between treatment groups with adjustment for diagnosis group.

matter or cerebrospinal fluid volumes in these regions. We found no significant differences between treatment groups in the apparent diffusion coefficient or fractional anisotropy in any regions analyzed by DTI and no differences in the T2 value for water or metabolite concentrations measured by magnetic resonance spectroscopy (MRS).

\section{D-TGA Subgroup Analysis}

Because infants with D-TGA are relatively homogeneous, rarely have chromosomal abnormalities, and have longer intraoperative support times, the impact of different perfusion strategies might be easier to detect within this diagnostic group. Infants with D-TGA randomized to the $25 \%$ hematocrit group, compared with infants in the $35 \%$ hematocrit group, had significantly longer duration of hospitalization (median 9 days, interquartile range $7-10$ days, vs median 7 days, interquartile range $6-9$ days; $P=.04$ ). No other perioperative or 1-year outcome variables differed among D-TGA patients assigned to the two treatment groups, although statistical power was limited.

TABLE 6. Qualitative and quantitative evaluation of magnetic resonance imaging outcomes according to treatment group

\begin{tabular}{|c|c|c|c|}
\hline Variable & $25 \%$ Hematocrit $(n=25)$ & $35 \%$ Hematocrit $(n=23)$ & $P$ value* \\
\hline Qualitative analysis & \multicolumn{2}{|c|}{ No. with abnormality (\%) } & \multirow{4}{*}{1.0} \\
\hline Focal or multifocal abnormalities & $9(36)$ & $10(43)$ & \\
\hline Focal infarction or atrophy & $1(4)$ & 0 & \\
\hline Brain mineralization/hemosiderin & $8(32)$ & $10(43)$ & \\
\hline Diffuse abnormalities & $2(8)$ & $1(4)$ & \multirow[t]{4}{*}{1.0} \\
\hline Delayed myelination & $1(4)$ & 0 & \\
\hline Ventriculomegaly & $1(4)$ & 0 & \\
\hline T2 hyperintensities/gliosis/periventricular leukomalacia & $1(4)$ & $1(4)$ & \\
\hline Developmental abnormalities & $1(4)$ & $3(13)$ & 1.0 \\
\hline Major malformation & 0 & 0 & \\
\hline Minor malformation & $1(4)$ & $3(13)$ & \\
\hline Quantitative analysis & \multicolumn{2}{|c|}{ Mean $\pm S D$} & \\
\hline Head circumference (cm) & $46.1 \pm 1.6$ & $46.4 \pm 1.3$ & $.37 \dagger$ \\
\hline \multicolumn{4}{|l|}{ Volumetric analysis (total, $\mathrm{mL}$ ) } \\
\hline Gray matter & $599 \pm 63$ & $628 \pm 58$ & $.08 \dagger$ \\
\hline Subcortical gray matter & $32 \pm 10$ & $33 \pm 10$ & $.65 \dagger$ \\
\hline Myelinated white matter & $76 \pm 28$ & $83 \pm 39$ & $.42 \dagger$ \\
\hline Unmyelinated white matter & $181 \pm 40$ & $170 \pm 45$ & $.61 \dagger$ \\
\hline CSF & $100 \pm 34$ & $103 \pm 33$ & $.55 \dagger$ \\
\hline Intracranial (brain + CSF) & $988 \pm 99$ & $1017 \pm 106$ & $.16 \dagger$ \\
\hline Brain & $888 \pm 88$ & $914 \pm 93$ & $.18 \dagger$ \\
\hline Cerebrum & $789 \pm 82$ & $812 \pm 85$ & $.20 \dagger$ \\
\hline Cerebellum & $99 \pm 10$ & $102 \pm 11$ & $.19 \dagger$ \\
\hline \multicolumn{4}{|l|}{ Spectroscopy analysis } \\
\hline $\mathrm{T} 2$ (ms) & $99 \pm 6$ & $100 \pm 5$ & $.66 \dagger$ \\
\hline $\mathrm{N}$-acetyl aspartate $(\mathrm{mmol} / \mathrm{L})$ & $7.7 \pm 2.4$ & $7.9 \pm 1.4$ & $.90 \dagger$ \\
\hline
\end{tabular}

CSF, Cerebrospinal fluid. ${ }^{*} P$ values, determined by means of stratified exact tests, are for differences between treatment groups with adjustment for diagnosis group. $\dagger P$ values, determined by means of linear regression, are for differences between treatment groups with adjustment for diagnosis group and age at evaluation by magnetic resonance imaging. 


\section{Discussion}

We found that neonates and infants assigned to the $25 \%$ compared with the $35 \%$ hematocrit strategy had similar early postoperative hemodynamic and later neurodevelopmental outcomes. Infants randomized to the $25 \%$ strategy, compared with the 35\% strategy, had greater positive fluid balance from the onset to cessation of bypass; lower serum osmolality during the cooling phase of bypass; lower intraoperative perfusion pressures; and lower ionized calcium during rewarming and warm flow. They also had significantly lower regional oxygen saturation at 10 minutes after cooling and onset of low flow, as well as a tendency to be lower at the start of rewarming, 10 minutes after start of rewarming, and at resumption of CPB at full flow. However, the clinical significance of these differences is likely to be negligible because the actual regional oxygen saturation values were high and well above a $45 \%$ threshold for neurologic injury recently reported. ${ }^{13}$ A slightly higher 24-hour inotrope score among infants in the 35\% group was not associated with adverse clinical outcomes. A prespecified subgroup analysis demonstrated that infants with D-TGA randomized to the $35 \%$ hematocrit group, compared with the $25 \%$ group, were discharged from the hospital significantly sooner. Otherwise, the treatment groups had no significant differences or suggestive trends in other early postoperative outcomes, including blood product usage and adverse events. At age 1 year, the treatment groups had similar MDI and PDI scores; developmental scores in both treatment groups were highly significantly worse than the population norms. Thus, hemodilution to hematocrit levels of 35\% compared with $25 \%$ had no significant clinical benefits or risks overall among infants undergoing 2-ventricle repair without aortic arch reconstruction.

Both qualitative and quantitative analyses of MRI data obtained in a subset of our population showed no major differences between treatment groups. This finding suggests that overt acquired brain injury detectable by MRI could not be attributed to hematocrit strategy. The small but statistically significant differences in gray matter volume found in two regions (premotor and subgenual) will require further analysis with regard to their relationship to functional outcome. Interestingly, a reduced volume in the premotor region (gray and white matter combined) was correlated with IQ in one previous study of the effect of premature birth on brain volumes in childhood. ${ }^{14}$ However, we found no difference in neurodevelopmental outcome between treatment groups in our study; hence, the small volume differences we found probably represent a minor effect. The potential significance of these findings will be addressed in future work. Finally, previous investigations have reported a high incidence of embolic stroke ${ }^{15}$ and periventricular leukoencephalopathy ${ }^{16,17}$ in similar populations studied by brain MRI. We did not perform preoperative or early postoperative brain MRIs. Therefore, we cannot determine whether the absence of infarction and the low prevalence of periventricular leukoencephalopathy in our study population are related to institutional differences in perioperative management or resolution of findings that had been present earlier.

We excluded infants who were believed or proven to have genetic syndromes during routine clinical care, but we did not perform fluorescent in situ hybridization studies on all infants. Genetic and other patient factors have been highly associated with low developmental scores among infants undergoing heart surgery, ${ }^{18}$ and it is likely that such factors explain, in part, the low developmental scores of infants in both treatment groups at age 1 year. Because the predictive validity of infant neurocognitive testing is limited, it is possible that differences between the two hemodilution strategies could emerge with longer follow-up. ${ }^{19,20}$ However, the predictive validity of the Bayley Scales is better in high-risk infants than that in normal children, ${ }^{21,22}$ and we have seen treatment differences in other randomized trials of other aspects of perfusion strategies. Our study sample excluded children with other known risk factors for adverse neurodevelopmental outcome. This, together with the single-center design and exclusion of the highest risk infants with single ventricle, may limit the generalizability of the findings.

In summary, early postoperative and 1-year developmental outcomes are similar among infants undergoing reparative cardiac operations using hemodilution to hematocrit levels of $35 \%$ compared with $25 \%$, although intraoperative fluid accumulation is greater with a lower hematocrit value. Administration of blood products and occurrence of adverse events are comparable with these hemodilution strategies. Infants with D-TGA in the $35 \%$ hematocrit group had a shorter hospital stay, although they did not differ with respect to other outcome variables. Overall, in infants undergoing repair of congenital heart disease with 2 ventricles and without aortic arch obstruction, higher versus lower hematocrit levels within the range of $25 \%$ to $35 \%$ have no significant advantages or disadvantages. ${ }^{18}$

\section{References}

1. Jonas RA, Wypij D, Roth SJ, Bellinger DC, Visconti KJ, du Plessis $\mathrm{AJ}$, et al. The influence of hemodilution on outcome after hypothermic cardiopulmonary bypass: results of a randomized trial in infants. J Thorac Cardiovasc Surg. 2003;126:1765-74.

2. du Plessis AJ, Jonas RA, Wypij D, Hickey PR, Riviello J, Wessel DL, et al. Perioperative effects of alpha-stat versus $\mathrm{pH}$-stat strategies for deep hypothermic cardiopulmonary bypass in infants. $J$ Thorac Cardiovasc Surg. 1997;114:991-1000.

3. Wernovsky G, Wypij D, Jonas RA, Mayer JE Jr, Hanley FL, Hickey PR, et al. Postoperative course and hemodynamic profile after the arterial switch operation in neonates and infants: a comparison of low-flow cardiopulmonary bypass versus circulatory arrest. Circulation. 1995;92:2226-35.

4. Novak I, Davies PSW, Elliot MJ. Noninvasive estimation of total body water in critically ill children after cardiac operations. J Thorac Cardiovasc Surg. 1992;104:585-9. 
5. Pollack MM, Patel KM, Ruttimann UE. PRISM III: an updated Pediatric Risk of Mortality score. Crit Care Med. 1996;24:743-52.

6. Warfield SK, Kaus M, Jolesz FA, Kikinis R. Adaptive, template moderated, spatially varying statistical classification. Med Image Anal. 2000;4:43-55.

7. Huppi PS, Warfield S, Kikinis R, Barnes PD, Zientara GP, Jolesz FA, et al. Quantitative magnetic resonance imaging of brain development in premature and mature newborns. Ann Neurol. 1998;43:224-35.

8. Haidar H, Warfield SK, Soul JS. Talairach-based parcellation of neonatal brain magnetic resonance imaging data: validation of a new approach. J Neuroimaging. 2005;15:305-14.

9. Maier SE, Gudbjartsson H, Patz S, Hsu L, Lovblad KO, Edelman RR, et al. Line scan diffusion imaging: characterization in healthy subjects and stroke patients. Am J Roentgenol. 1998;171:85-93.

10. Kreis R, Ernst T, Ross BD. Development of the human brain: in vivo quantification of metabolite and water content with proton magnetic resonance spectroscopy. Magn Reson Med. 1993;30:424-37.

11. Christiansen P, Henriksen O, Stubgaard M, Gideon P, Larsson HB. In vivo quantification of brain metabolites by $1 \mathrm{H}-\mathrm{MRS}$ using water as an internal standard. Magn Reson Imaging. 1993;11:107-18.

12. Bayley N. Bayley scales of infant development. 2nd ed. San Antonio [TX]: The Psychological Corporation; 1993.

13. Dent CL, Spaeth JP, Jones BV, Schwartz SM, Glauser TA, Hallinan B, et al. Brain magnetic resonance imaging abnormalities after the Norwood procedure using regional cerebral perfusion. $J$ Thorac Cardiovasc Surg. 2006;131:190-7.

14. Peterson BS, Vohr B, Staib LH, Cannistraci CJ, Dolberg A, Schneider $\mathrm{KC}$, et al. Regional brain volume abnormalities and long-term cognitive outcome in preterm infants. JAMA. 2000;284:1939-47.
15. McQuillen PS, Hamrick SEG, Perez M, Barkovich AJ, Glidden DV, Karl TR, et al. Balloon atrial septostomy is associated with preoperative stroke in neonates with transposition of the great arteries. Circulation. 2006;113:280-5.

16. Mahle WT, Tavani F, Zimmerman RA, Nicolson SC, Galli KK, Gaynor JW, et al. An MRI study of neurological injury before and after congenital heart surgery. Circulation. 2002(12 Suppl 1);106: I109-14.

17. Galli KK, Zimmerman RA, Jarvik GP, Wernovsky G, Kuypers MK, Clancy RR, et al. Periventricular leukomalacia is common after neonatal cardiac surgery. J Thorac Cardiovasc Surg. 2004;127: 692-704.

18. Wernovsky G, Shillingford AJ, Gaynor JW. Central nervous system outcomes in children with complex congenital heart disease. Curr Opin Cardiol. 2005;20:94-9.

19. Ross G. Some thoughts on the value of infant tests for assessing and predicting mental ability. J Dev Behav Pediatr. 1989;10:44-7.

20. Ulvund S. Predictive validity of assessments of early cognitive competence in light of some current issues in developmental psychology. Hum Dev. 1984;27:76-83.

21. Kopp C, McCall R. Predicting later mental performance for normal, at risk, and handicapped infants. In: Baltes $\mathrm{P}$, Brim $\mathrm{O}$, editors. Life-span development and behavior. New York: Academic Press; 1982. p. 33.

22. McGrath E, Wypij D, Rappaport LA, Newburger JW, Bellinger DC. Prediction of IQ and achievement at age 8 years from neurodevelopmental status at age 1 year in children with D-transposition of the great arteries. Pediatrics. 2004;114:e572-6.

\section{New Editorial Office}

Effective January 1, 2008, Lawrence H. Cohn, MD is editor of The Journal of Thoracic and Cardiovascular Surgery.

Please direct all queries to:

Ryan Walther, Managing Editor

Journal of Thoracic and Cardiovascular Surgery

American Association for Thoracic Surgery

900 Cummings Center, Suite 221-U

Beverly, MA 01915

Telephone: 978-299-4505

Fax: 978-524-8890

E-mail: jtcvs@aats.org

Continue to submit all manuscripts to Editorial Manager at http://www.editorialmanager.com/jtcvs. 


\section{E-Appendix: Methods}

Anesthesia and perfusion methods. After induction of anesthesia and placement of an arterial catheter, surface cooling was initiated with a low ambient room temperature, a cooling mattress, and ice packs to the head. CPB and core cooling were begun as soon as the venous and aortic cannulas were in place. Patients had variable periods of full-flow CPB at approximately $2.5 \mathrm{~L} \cdot \min ^{-1} \cdot \mathrm{m}^{-2}$ when cooling to various levels of hypothermia and usually during rewarming. Some patients had periods of deep hypothermic circulatory arrest, and most had at least one period of reduced-flow $\mathrm{CPB}$, for example, at approximately $0.75 \mathrm{~L} \cdot \min ^{-1}$ . $\mathrm{m}^{-2}$ when at deep hypothermia (rectal temperature $<18^{\circ} \mathrm{C}$ ). Hypothermic myocardial protection was provided by infusion of oxygenated crystalloid cardioplegic solution (Plegisol; Abbott Laboratories, North Chicago, Ill) usually as a single dose of 20 $\mathrm{mL} / \mathrm{kg}$ or a custom mix of 4 parts crystalloid (Baxter Compass, Edison, $\mathrm{NJ}$ ) to 1 part blood. After patient randomization, hemodilution was achieved with whole blood and Plasma-Lyte A pH 7.4 (Multiple Electrolytes Injection, Type 1, USP). Standard perfusion calculations were used to determine the volumes of the priming constituents, with the aim of obtaining a hematocrit level of $25 \%$ or $35 \%$ at the time of onset of low-flow CPB. The $\mathrm{pH}$-stat strategy was used during core cooling, low-flow hypothermic perfusion, and rewarming up to $30^{\circ} \mathrm{C}$. ${ }^{\mathrm{E} 1}$ Anesthetic management and other aspects of perfusion on CPB were identical for both treatment groups. We used conventional ultrafiltration during $\mathrm{CPB}$, but not modified ultrafiltration after CPB.

Regional cerebral oximetry. Regional cerebral oxygen saturation was measured with the INVOS 5100 spectrometer (Somanetics; Troy, Mich). The INVOS 5100 is a continuous-wave spectrometer and uses two wavelengths of near-infrared light (730 and $810 \mathrm{~nm}$ ) to measure the ratio of oxyhemoglobin to total hemoglobin. The cerebral oxygen saturation is expressed as the regional oxygen saturation, the scale unit of which is percent. After the induction of anesthesia, Pediatric SomaSensors (Somanetics, Troy, Mich) were placed on the right and the left sides of the forehead according to the manufacturer's guidelines. After an accommodation period, data collection was begun and downloaded to storage disk every 10 seconds throughout the case for further analysis.

Transcranial Doppler. A 2-MHz, range-gated, pulsed-wave transcranial Doppler sonographic probe (Multi-Dop T; DWL Elektronische Systeme GmbH, Sipplingen, Germany) was placed over the right (rarely the left) temporal window to measure cerebral blood flow velocity in the proximal (M1) segment of the middle cerebral artery. To ensure a reproducible window, we adjusted the signal from the artery to be accompanied by retrograde anterior (A1 segment) cerebral artery flow. After an acceptable waveform had been achieved, the probe position was secured with an adhesive tape and head bandage. Meticulous care was taken to ensure a constant position, insonation depth, sample volume, gain, and power of ultrasound for all measurements. Peak systolic flow velocity $\left(\mathrm{V}_{\mathrm{S}}\right)$, mean flow velocity $\left(\mathrm{V}_{\mathrm{M}}\right)$, and peak end-diastolic flow velocity $\left(\mathrm{V}_{\mathrm{D}}\right)$ were measured during hemodynamically stable intervals, with constant recordings of at least 15 seconds' duration, at 6 time points: after induction, at heparin administration, 10 minutes after cooling on $\mathrm{CPB}, 10$ minutes after start of rewarming on $\mathrm{CPB}$, rewarmed to $35^{\circ} \mathrm{C}$ on $\mathrm{CPB}, 60$ minutes off $\mathrm{CPB}, 6$ hours after $\mathrm{CPB}$, and 18 hours after $\mathrm{CPB}$. Middle cerebral artery pulsa- tility index (PI) and resistance index (RI) were calculated according to the following formulas:

$$
\begin{aligned}
& \mathrm{PI}=\left[\mathrm{V}_{\mathrm{S}}-\mathrm{V}_{\mathrm{D}}\right] / \mathrm{V}_{\mathrm{M}} \\
& \mathrm{RI}=\left[\mathrm{V}_{\mathrm{S}}-\mathrm{V}_{\mathrm{D}}\right] / \mathrm{V}_{\mathrm{S}}
\end{aligned}
$$

In addition, mean arterial pressure, $\mathrm{PaCO}_{2}, \mathrm{pH}$, bypass flow rates, and tympanic, esophageal, and rectal temperatures were recorded at the same times.

Early postoperative data. We measured serum lactate 60 minutes after CPB, as well as at 3, 9, 12, 18, and 24 hours postoperatively. During the first 24 hours after surgery, cardiac output was determined by the thermodilution technique ${ }^{\mathrm{E} 2}$ at 3-hour intervals. During the study period, cardiac outputs were measured primarily in the patients of one participating surgeon (R.A.J.), for whom placement of a thermodilution catheter was performed as part of routine clinical care. The study nurses recorded daily data on events, medications, respiratory status, laboratory studies, fluid inputs and outputs, and blood product requirements. Bioelectric impedance was measured preoperatively and on the first postoperative day to estimate total body water. ${ }^{\text {E3 }}$ Inotrope score, modified from Wernovsky and associates, ${ }^{\mathrm{E} 2}$ was determined for the initial 24 hours postoperatively. Modified PRISM III scores were also calculated for each patient at 12 and 24 hours postoperatively. ${ }^{\text {E4 }}$

Neurologic examination. Neurologic examination was performed before surgery and at 1-year follow-up according to a uniform protocol. Patients were classified as having abnormal results of the neurologic examination if definite abnormalities were noted in any of the following categories: head circumference, mental status, special senses, cranial nerve motor function, or peripheral motor function.

Brain MRI. MRI scans were acquired at 1 year of age. Conventional MRI data were obtained for qualitative evaluation, and volumetric, diffusion tensor, and spectroscopy data were obtained for detailed quantitative analysis of brain structure and composition. One neuroradiologist (R.R.) evaluated all the MRI scans for any congenital or acquired abnormalities. For volumetric analysis, a sequence of image processing algorithms was used to register and then segment coronal T1-weighted and T2-weighted MRI data into separate tissue classes: cortical and subcortical gray matter, myelinated and unmyelinated white matter, and cerebrospinal fluid. ${ }^{\text {E5,E6 }}$ The segmented data were then parcellated into 16 regions with semiautomated Talairach-based parcellation software, which has been validated specifically in infant brain MRI data. ${ }^{\mathrm{E} 7}$ DTI data were obtained by the line scan diffusion imaging technique. $^{\mathrm{E} 8}$ We obtained axial DTI data with 6 directions and $\mathrm{b}$ factors of 5 and 750. The apparent diffusion coefficient and fractional anisotropy were measured offline in selected regions of interest of the cerebral white matter (frontal, central, and posterior white matter, optic radiations, posterior limb of the internal capsule, and the genu and splenium of the corpus callosum). Finally, we obtained single voxel proton MRS to measure the concentration of specific metabolites in the left posterior cerebral white matter that may be altered by injury. Three MRS sequences were obtained sequentially with echo time values of 31, 135, and $270 \mathrm{~ms}$ (repetition time1500, voxel volume $1.5 \mathrm{~cm}^{3}$ ). We calculated the T2 value for water (in milliseconds, using the water unsuppressed spectra) and calculated the absolute metabolite concentrations of choline, creatine, and $N$-acetyl aspartate (in millimoles per liter) using the water standardization method. ${ }^{\mathrm{E} 9, \mathrm{E} 10}$ 
Developmental evaluation. Two examiners administered the Bayley Scales of Infant Development, ${ }^{\text {E11 }}$ which yields scores on two indexes: the PDI and the MDI. We also calculated the proportion of children whose scores were $\leq 85$ or 70 (at least $1 \mathrm{SD}$ or $2 \mathrm{SD}$ below the population mean, respectively).

Statistical analyses. The treatment groups were compared in intention-to-treat analyses. Secondary analyses examined the effect of hematocrit level at the onset of low-flow CPB as a continuous variable. For patients in whom low-flow bypass was not used, we analyzed the hematocrit level 10 minutes after onset of cooling. All tests of hypotheses and regression analyses of outcome variables were adjusted for diagnostic group (D-TGA, tetralogy of Fallot, and VSD groups). Volumetric, diffusion tensor, and spectroscopy MRI outcome variables were also adjusted for age at MRI evaluation. We also assessed potential interactions between hemodilution treatment assignment and diagnostic group on outcomes. Primary outcome variables were serum lactate levels measured 60 minutes after $\mathrm{CPB}$ in the perioperative period and PDI scores at age 1 year.

Outcomes included both continuous and categorical variables. Linear regression and exact stratified Wilcoxon tests were used to analyze continuous variables. Stratified exact tests and logistic regression methods were used to analyze categorical variables. In addition to diagnostic group, we performed analyses assessing whether other potential predictor variables confounded the effects of hemodilution on primary outcome variables. These predictor variables included surgeon, sex, age at the time of the operation, interval between the operation and developmental examination, birth weight, maternal and paternal education, family social class, gestational age, Apgar scores at 1 and 5 minutes, preoperative intubation, preoperative acidosis, calendar date of the operation, preoperative neurologic examination results, type of cardioplegic solution, lowest tympanic temperature, duration of circulatory arrest, total bypass time, total support time, and individual performing developmental testing.

All $P$ values are 2-tailed. A sample size of 60 subjects per treatment group provides $78 \%$ power to detect a half SD difference (effect size $0.5 \mathrm{SD}$ units) and $91 \%$ power to detect an effect size of $0.6 \mathrm{SD}$ units between treatment groups in either lactate levels or PDI scores.

We are indebted to members of our Data and Safety Monitoring Board: Welton Gersony, MD (Chairman), Nathan J. Blum, MD,
Erle Austin, MD, Sally A. Hunsberger, PhD, John P. Lantos, MD, and Eli Mizrahi, MD; Haim Bassan, MD, and Cecil Hahn, MD, for conducting neurologic examinations; our perfusionists: Willis G. Gieser, CCP, Robert A. LaPierre, BS, CCP, Robert J. Howe, BS, CCP, Gregory S. Matte, CCP, and William L. Regan; our nursing staff in the Cardiac Intensive Care Unit for assistance with adherence to the protocol; families and children in the cohort for their time and effort; Ludmila Kyn for database and statistical programming; Donna Donati, Donna Duva, and Lisa-Jean Buckley for data management; and Kathleen Alexander for project coordination.

\section{E-References}

E1. du Plessis AJ, Jonas RA, Wypij D, Hickey PR, Riviello J, Wessel $\mathrm{DL}$, et al. Perioperative effects of alpha-stat versus $\mathrm{pH}$-stat strategies for deep hypothermic cardiopulmonary bypass in infants. $J$ Thorac Cardiovasc Surg. 1997;114:991-1000.

E2. Wernovsky G, Wypij D, Jonas RA, Mayer JE Jr, Hanley FL, Hickey $\mathrm{PR}$, et al. Postoperative course and hemodynamic profile after the arterial switch operation in neonates and infants: a comparison of low-flow cardiopulmonary bypass versus circulatory arrest. Circulation. 1995;92:2226-35.

E3. Novak I, Davies PSW, Elliot MJ. Noninvasive estimation of total body water in critically ill children after cardiac operations. J Thorac Cardiovasc Surg. 1992;104:585-89.

E4. Pollack MM, Patel KM, Ruttimann UE. PRISM III: an updated Pediatric Risk of Mortality score. Crit Care Med. 1996;24:743-52.

E5. Warfield SK, Kaus M, Jolesz FA, Kikinis R. Adaptive, template moderated, spatially varying statistical classification. Med Image Anal. 2000;4:43-55

E6. Huppi PS, Warfield S, Kikinis R, Barnes PD, Zientara GP, Jolesz FA, et al. Quantitative magnetic resonance imaging of brain development in premature and mature newborns. Ann Neurol. 1998;43: 224-35.

E7. Haidar H, Warfield SK, Soul JS. Talairach-based parcellation of neonatal brain magnetic resonance imaging data: validation of a new approach. J Neuroimaging. 2005;15:305-14.

E8. Maier SE, Gudbjartsson H, Patz S, Hsu L, Lovblad KO, Edelman $\mathrm{RR}$, et al. Line scan diffusion imaging: characterization in healthy subjects and stroke patients. Am J Roentgenol. 1998;171:85-93.

E9. Kreis R, Ernst T, Ross BD. Development of the human brain: in vivo quantification of metabolite and water content with proton magnetic resonance spectroscopy. Magn Reson Med. 1993;30:424-37.

E10. Christiansen P, Henriksen O, Stubgaard M, Gideon P, Larsson HB In vivo quantification of brain metabolites by $1 \mathrm{H}-\mathrm{MRS}$ using water as an internal standard. Magn Reson Imaging. 1993;11:107-18.

E11. Bayley N. Bayley scales of infant development. 2nd ed. San Antonio [TX]: The Psychological Corporation; 1993. 


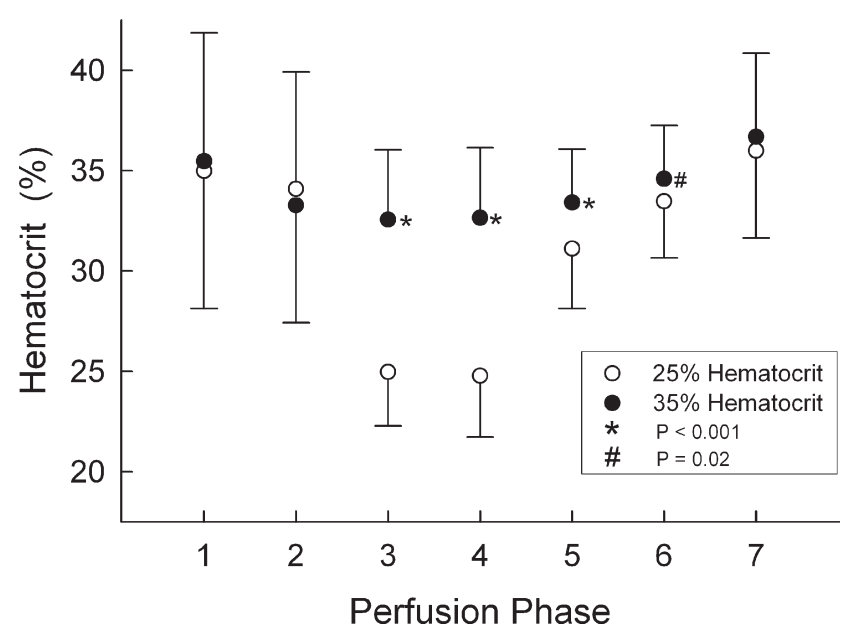

Figure E1. Plot of serial measurements of hematocrit according to perfusion phases, defined as follows: $1=$ after induction of anesthesia; 2 = heparin given; $3=10$ minutes after onset of cooling; 4 = onset of low-flow bypass; $5=10$ minutes after onset of rewarming; $6=$ start of warm flow; $7=60$ minutes off bypass. Values are depicted as the mean \pm 1 standard deviation. After adjustment for diagnostic group, statistically significant differences were found for phases $3,4,5$, and 6 .

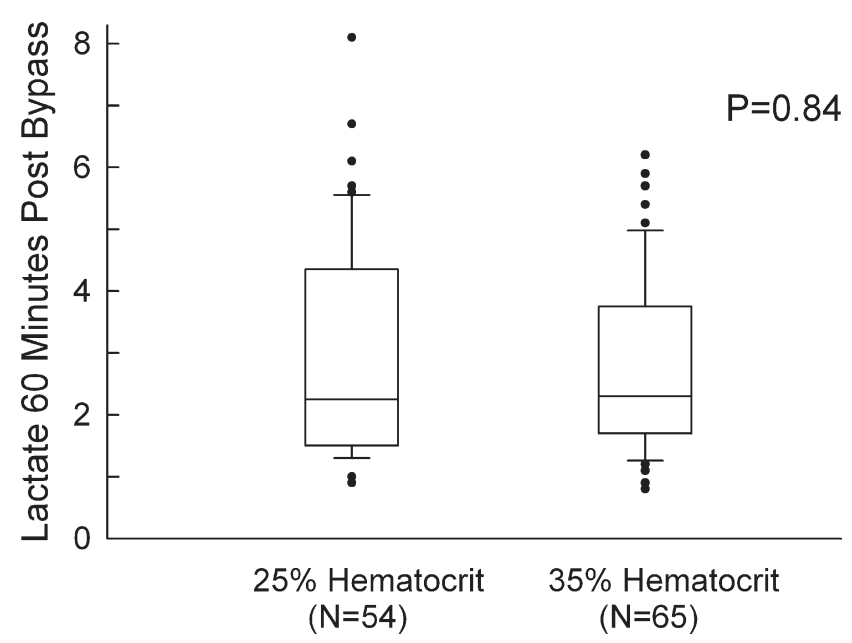

Figure E2. Box plots of serum lactate levels measured 60 minutes after cessation of cardiopulmonary bypass according to hematocrit group. The solid bar within the box represents the median value, the upper boundary of the box the 75th percentile, and the lower boundary of the box the 25th percentile. The vertical lines extend to the 10th and 90th percentiles, with more extreme observations plotted as circles. The linear regression $P$ value shown is for the effect of hematocrit group on lactate level, with adjustment for diagnostic group. 


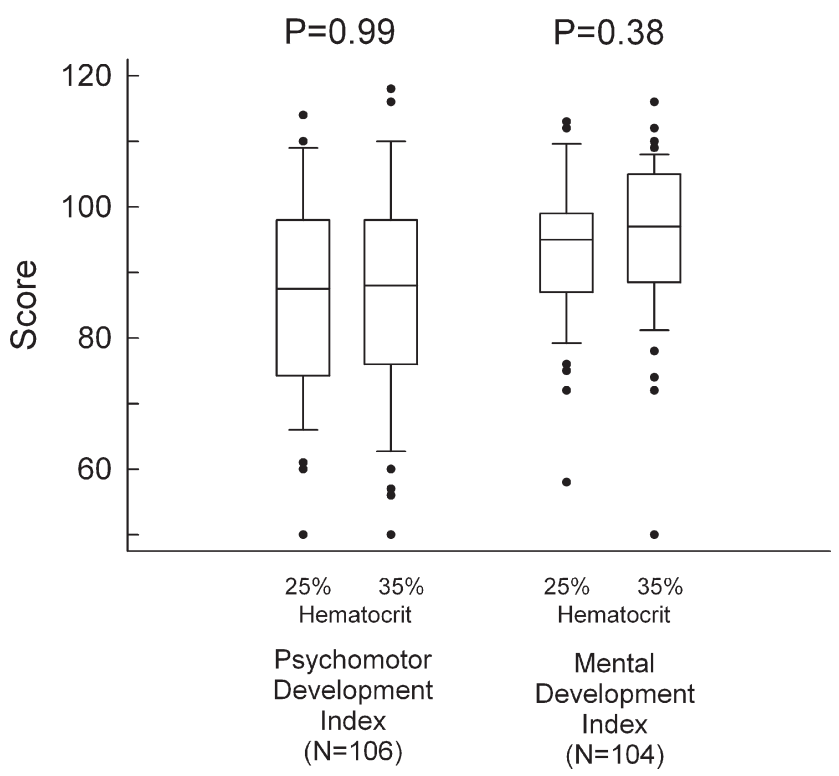

Figure E3. Box plots of Psychomotor Development Index and Mental Development Index scores at 1 year, according to hematocrit group. The solid bar within the box represents the median value, the upper boundary of the box the 75th percentile, and the lower boundary of the box the 25th percentile. The vertical lines extend to the 10th and 90th percentiles, with more extreme observations plotted as circles. The linear regression $\boldsymbol{P}$ values shown are for the effect of hematocrit group on outcome, with adjustment for diagnostic group.

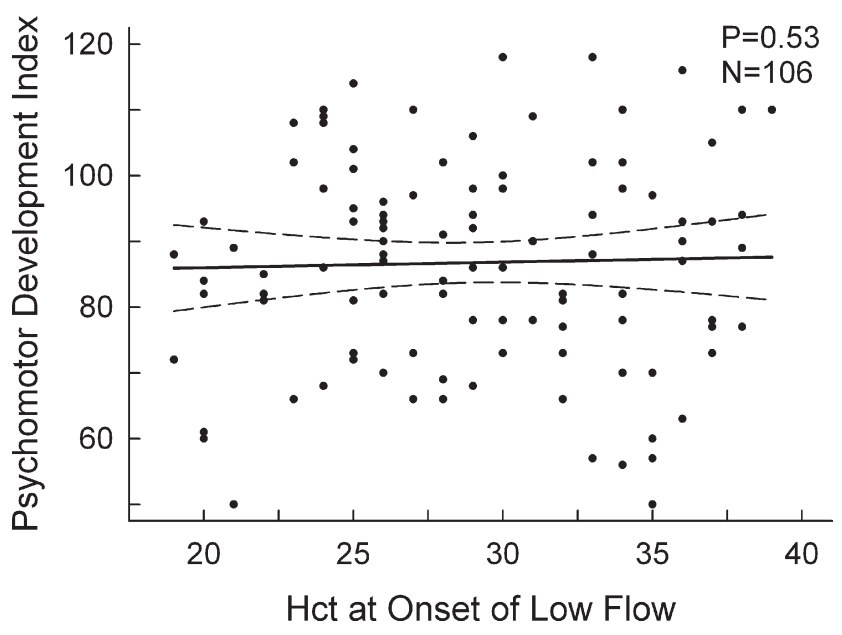

Figure E4. Scatterplot of Psychomotor Development Index scores at 1 year as a function of hematocrit at the onset of low-flow bypass. The solid line was derived by linear regression of the data, and the dashed lines delimit the $95 \%$ confidence interval. The linear regression $\boldsymbol{P}$ value shown is for the effect of hematocrit at the onset of low-flow bypass on outcome, with adjustment for diagnostic group. Hct, Hematocrit. 